\title{
INVESTIGACIONES
}

de HISTORIA ECONÓMICA

2006, otoño, número 6. Pp. 41 a 72

\section{Recuperación y expansión de la agroindustria azucarera mexiquense en un contexto de crisis (1821-1854)}

\author{
Recovery and expansion of the sugar agro-industry \\ of the State of Mexico in a context of crisis (1821-1854) \\ ERNEST SÁNCHEZ SANTIRÓ \\ Instituto de Investigaciones Dr. José María Luis Mora, México
}

\begin{tabular}{|c|c|}
\hline RESUMEN & ABSTRACT \\
\hline $\begin{array}{r}\text { El trabajo analiza la agroindustria azucarera } \\
\text { del estado de México en la primera mitad del } \\
\text { siglo XIX a partir de tres factores: la } \\
\text { producción de azúcar, aguardiente de caña y } \\
\text { miel, sus mercados y las redes comerciales. } \\
\text { Con relación a ellos, el artículo realiza una } \\
\text { contribución a la discusión general sobre el } \\
\text { desempeño de la economía mexicana en dicha } \\
\text { época, mostrando un comportamiento } \\
\text { regional diferencial. }\end{array}$ & $\begin{array}{l}\text { This work analyses the sugar agro-industry of } \\
\text { the State of Mexico, during the first haft of } \\
\text { nineteenth century from three main issues: the } \\
\text { production of sugar, cane rum and sugar-cane } \\
\text { syrup; their markets and the commercial } \\
\text { networks. Related to these issues, the article } \\
\text { realizes a contribution of the general } \\
\text { discussion on the operation of Mexican } \\
\text { economy in this period, showing a regional } \\
\text { differential activity. }\end{array}$ \\
\hline $\begin{array}{l}\text { PALABRAS CLAVE: Azúcar, Producción, } \\
\text { Mercados, Morelos, México, Siglo XIX }\end{array}$ & $\begin{array}{l}\text { KEYWORDS: Sugar, Production, Markets, } \\
\text { Morelos, Mexico, 19th Century }\end{array}$ \\
\hline Códigos JEL: N36, N56, N76, Q13 & JEL Codes: N36, N56, N76, Q13 \\
\hline
\end{tabular}




\section{Introducción 1}

$\mathrm{L}$

a historiografía indica que la economía mexicana de la primera mitad del siglo XIX se encontraba en una situación de crisis y estancamiento o mostraba leves signos de crecimiento, en este último caso, a partir de la década de 1840. Sin embargo, existen matices en esta caracterización global, los cuales se hallan resumidos en un trabajo de Richard J. Salvucci, en el cual se presentan las tres posturas básicas sobre el desempeño de la economía mexicana en el período 1800-1840². Primeramente, aquél esboza la posición de historiadores como John Coatsworth, según la cual el producto per capita de la economía mexicana habría descendido entre 1800 y $1845^{3}$. El origen de la recesión estaría en la guerra de insurgencia que habría impactado sobre la debilitada economía novohispana tardocolonial. En esta misma línea de pensamiento se inscribe la postura de Enrique Cárdenas, cuando afirma que el conflicto armado generó pérdidas netas de mano de obra e infraestructuras agrícolas, el abandono e inundación de ciertos reales mineros, la ruina de la actividad artesanal, especialmente de la textil, así como un intenso proceso de descapitalización. Sus efectos se prolongarían durante toda la primera mitad del siglo XIX, en la medida en que provocaron la disminución del producto interno bruto mexicano entre 1800 y $1860^{4}$. En segundo lugar, Salvucci anota una visión alternativa sobre la economía mexicana en ese mismo lapso, sustentada en estadistas de la época, caso de Lucas Alamán, y en los análisis regionales realizados por ciertos historiadores contemporáneos: Margaret Chowning para el caso de la agricultura de Michoacán, Guy Thomson para el sector de la industria textil poblana o Juan Carlos Garavaglia y Juan Carlos Grosso para la agricultura de este mismo territorio. En estas obras se considera que la economía creció a un ritmo superior al supuesto en el anterior planteamiento, en especial, durante el decenio de $1840^{5}$. Finalmente, el propio Salvucci señala una tercera postura que tendría dos vertientes: el rechazo al enfoque que habla de la existencia de una depresión gene-

[Fecha de recepción del original, enero de 2006. Versión definitiva, mayo de 2006]

1 Un primer avance de los resultados aquí expuestos se presentó en el XXV Coloquio de Antropología e Historia Regionales. Historia, Nación y Región, organizado por El Colegio de Michoacán en octubre de 2003 y en un artículo referido exclusivamente al azúcar, sin tener en cuenta las otras dos producciones básicas relacionadas con dicha agroindustria: el aguardiente y la miel de caña (Sánchez Santiró, 2004). Agradezco a los evaluadores anónimos de Investigaciones de Historia Económica sus sugerencias, que me han permitido mejorar el texto.

2 Salvucci (1999).

3 En ciertas estimaciones, este mismo autor prolonga el descenso en el ingreso per capita hasta después de 1860 (Coatsworth, 1990, pp. 77-78 y 81-82).

4 Cárdenas (2003). Diversos trabajos consideran que la renta nacional se habría reducido en casi un 50 por 100. Romero y Jáuregui (1986), p. 138, Salvucci y Salvucci (1993), p. 49.

$5 \quad$ Chowning (1999); Thomson (1989); Garavaglia y Grosso (1991). 
ralizada, catastrófica y sostenida durante la insurgencia pero que, a su vez, no niega que la economía mexicana de la primera mitad del siglo XIX vivió una larga etapa de estancamiento o, como mucho, de leve crecimiento, en la medida en que el incremento de la producción no pudo situarse por encima del impulso demográfico. En estas condiciones, apenas habría habido un aumento del producto per capita entre 1800 y $1840^{6}$.

A la vez que la historiografía económica presenta este panorama general, también afirma la existencia de otro fenómeno: la profunda regionalización de la economía mexicana en las tres primeras décadas de vida independiente — se habla en ocasiones de fragmentación-, que hundiría sus raíces en la evolución de la economía novohispana durante el conflicto militar insurgente. Una tendencia que habría provocado diversos ritmos y direcciones dispares en la vida económica de las regiones mexicanas tras la independencia, algo que era de esperar en un país que carecía de un mercado interno unificado ${ }^{7}$.

Así pues, crisis económica y fragmentación del espacio económico, serían las características de la vida económica de México entre 1821 y 1850. Con el objetivo de introducir matices y puntualizaciones en este panorama general, el actual trabajo analiza la agroindustria azucarera del Estado de México, un sector altamente mercantilizado desde el período colonial, haciendo énfasis en tres factores: la producción de las haciendas azucareras, los mercados a los cuales iba destinada y la conformación de las redes mercantiles que conectaban ambas realidades.

Como veremos, dicha agroindustria experimentó un período de recuperación y expansión de 1825 a $1854^{8}$, tras superar las dificultades generadas durante el conflicto político y militar acaecido entre 1810 y 1821, lo cual representa un fuerte contraste con el panorama general de crisis y fragmentación apuntado en un inicio. Con ello esperamos entablar un diálogo entre postulados ya enunciados, hipótesis y datos nuevos que enriquezca la comprensión de la economía mexicana en sus primeras décadas de vida independiente.

Salvucci (1999), pp. 272 y 279-280. Richard J. Salvucci ha reiterado los argumentos de la depresión económica mexicana de la primera mitad del siglo XIX con tintes parcialmente más negativos que los manifestados con anterioridad (Salvucci, 2005).

$7 \quad$ Salvucci y Salvucci (1993), p. 41, y Cerutti (1985), p. 8.

8 El límite de este crecimiento lo ubicamos en 1854, año del estallido de la revolución de Ayutla que impactó fuertemente sobre la economía azucarera del Estado de México: ocupaciones de haciendas, destrucción de sus linderos por parte de los pueblos circunvecinos, así como incipientes protestas de carácter salarial de los operarios de los campos de caña y los ingenios, todo lo cual retrajo la actividad inversora de los hacendados azucareros. 


\section{La agroindustria azucarera del Estado de México en el contexto nacional e internacional de la primera mitad del siglo XIX}

Como paso previo al análisis planteado, es conveniente ubicar al sector azucarero del Estado de México en el contexto nacional e internacional, con el propósito de determinar la importancia y significación de los fenómenos detectados. Un problema fundamental para acometer esta tarea es el estado actual de la historiografía sobre la agroindustria azucarera mexicana en el período 1800-1854. Se carece de series amplias sobre unidades productivas, volumen y composición de la producción, circuitos mercantiles y precios, datos a partir de los cuales se podría realizar un análisis comparativo satisfactorio 9 . Por ello, lo que a continuación aportamos son ciertos datos y reflexiones de autores de la época que delimitan la fisonomía general del sector azucarero, así como su transformación durante el período. Este procedimiento nos permite establecer una comparación preliminar con el decurso de dicho sector en el ámbito internacional, en especial con el gran productor decimonónico caribeño: Cuba.

En relación al volumen total de producción de azúcar en el país, sobresalen dos puntos de referencia. En primer lugar, las 19.000 toneladas anotadas por Alejandro de Humboldt para principios del siglo XIX (1803), de las que 16.000 eran para el consumo interno y sólo 3.000 para el mercado internacional ${ }^{10}$. Medio siglo después, en 1858, Antonio García Cubas registraba una producción anual de unas 18.400 toneladas, de las que una ínfima cantidad salía del país ${ }^{11}$. Es decir, a mediados del siglo XIX, la producción azucarera de México apenas se acercaba a la de principios de la centuria. Como dato general es una manifestación más de los problemas globales de la economía novohispano/mexicana que, tras la crisis del decenio de 1810 y principios del de 1820, inició un lento proceso de recuperación en las tres décadas siguientes. El estancamiento adquiere mayor relieve si recordamos que, en el mismo período, la producción azucarera cubana pasó de 54.906 toneladas en 1820 a 426.274 en 1858 , lo que representó una tasa de crecimiento anual espectacular, del 5,5 por 100, mientras que la producción mundial pasó de 400.000 a 1.770 .000 toneladas en esos mismos años, cifras que evidencian un ritmo de aumento también elevado, aunque algo menor, del orden del 4 por 100 anual $^{12}$.

En el caso concreto de los precios, no existe una estadística "nacional" para el período. Sólo contamos con una reconstrucción de los precios al mayoreo del azúcar en el principal mercado del país, la ciudad de México, que, lamentablemente, se interrumpe durante el lapso 1833-1847 (Crespo, 1995).

$10 \quad$ Humboldt (1966 [1803]), p. 287.

11 García Cubas (1988 [1858]), [s. p.].

12 Moreno Fraginals (1978), vol. III, pp. 35-40. 
A partir de estos parámetros, se vislumbra en términos comparativos lo acaecido con la agroindustria azucarera mexicana durante el siglo XIX. Si en 1820 la producción del dulce mexicano suponía, en el mejor de los casos, un tercio de la producción cubana — considerando que en ese año hubiese mantenido el nivel de 1803, cosa que no ocurrió ${ }^{13}$ — , en 1858 ya sólo representaba el 4 por 100. Este hecho es la comprobación de la evolución divergente de dos producciones organizadas con criterios dispares y en contextos muy diversos. Frente a una agroindustria azucarera cubana que iba ampliando su escala productiva (aumento del tamaño medio de las haciendas, incorporación creciente de mano de obra esclava, desarrollo de procesos de cambio tecnológico, etc.) con una orientación básica a la exportación (Europa y Estados Unidos) ${ }^{14}$, la agroindustria mexicana mantuvo, en términos generales ${ }^{15}$, la fisonomía que había adquirido a finales del siglo XVIII, es decir, un sector enfocado al consumo interno, con el agravante de que, tras 1821, se perdieron los escasos mercados internacionales a los que había accedido, no sin grandes dificultades, a raíz de la crisis de Haití de 1791. Entre 1821 y 1877, la producción azucarera mexicana vivió únicamente de los mercados internos, siendo la exportación algo anecdótico ${ }^{16}$. De hecho, ante la posible amenaza que hubiese podido representar la creciente producción cubana, con precios más competitivos que los mexicanos, el Congreso General determinó en 1824 la prohibición de importar cualquier variedad de azúcar a la República Mexicana ${ }^{17}$.

En este marco general, la producción azucarera del Estado de México, obtenida en el distrito de Cuernavaca y en el partido de Tenancingo ${ }^{18}$, tuvo un comportamiento claramente diferenciado, como puede apreciarse a continuación. En 1803, el cálculo ya citado de Humboldt situaba la producción novohispana en unas 19.000 toneladas, mientras que en esas mismas fechas las haciendas de tierra caliente de la Intendencia de México (en las subdelegaciones de Cuernavaca y Cuautla de Amilpas) generaban cerca de 7.820 toneladas, como promedio anual entre 1800 y 1804, lo que representaba el 41 por 100 del total virreinal ${ }^{19}$. En 1822, en el contexto de la

Un folleto de 1822 señalaba que la producción de azúcar en México ascendía, como mucho, a 12.700 toneladas. Apuntamientos (1822), pp. 9-10.

14 Santamaría (2005), pp. 719-726.

15 El único cambio cualitativo destacable fue la total abolición de la mano de obra esclava en las haciendas azucareras de México entre 1821 y 1826.

16 Crespo y Vega (1988), p. 623.

17 Sánchez Santiró (2004), p. 628.

18 El distrito de Cuernavaca formó parte del Estado de México desde su creación, en 1824, hasta 1869, cuando pasó a configurar lo que en la actualidad es, básicamente, el Estado de Morelos. El distrito estuvo integrado hasta 1849 por tres partidos: el homónimo, el de Cuautla de Amilpas (que pasó a denominarse Morelos) y, desde enero de 1825, el de Jonacatepec. Díez (1982), pp. CX, CXII y CXXVI-VII.

Sánchez Santiró (2001), p. 65. 
recién adquirida independencia, los valores de referencia eran los siguientes: unas 12.700 toneladas en el conjunto del país, de las cuales un 50 por 100 (6.348) se localizaban en las subdelegaciones antes citadas. Es decir, de manera absoluta, el sector se había visto severamente afectado por la guerra civil entre realistas e insurgentes con una reducción del 33 por 100 - aunque, proporcionalmente, la producción de la zona de tierra caliente al sur de la ciudad de México había sufrido un menor impacto, a diferencia de otras regiones como Michoacán o Veracruz ${ }^{20}$. A finales de la década de 1850, esta disímil evolución entre las regiones azucareras del país se había acentuado. En 1858 se estimaba que la fabricación de dulce en México rondaba las 18.400 toneladas, cantidad muy próxima al máximo histórico colonial de principios del siglo XIX. Sin embargo, el dato que sobresalía era la posición alcanzada por la agroindustria del distrito de Cuernavaca y el partido de Tenancingo: el 62 por 100 del azúcar del país (11.500 Tm) se obtenía en estas dos zonas ${ }^{21}$. El Estado de México, en tres décadas, había incrementando progresivamente su participación en el conjunto nacional, hasta adquirir una posición dominante, que mantendría hasta la revolución de 1910.

¿Cómo explicar una evolución tan diferente? El objetivo de los siguientes apartados es aportar los elementos que expliquen la disparidad entre el lento crecimiento azucarero en el ámbito nacional y el vivo dinamismo de la producción mexiquense, lo cual permite enriquecer nuestra comprensión sobre el distinto comportamiento regional y sectorial de la economía mexicana de la época.

\section{La producción azucarera del Estado de México}

La agroindustria azucarera mexiquense de la primera mitad del siglo XIX generaba cuatro mercancías fundamentales, a saber: azúcar, aguardiente de caña, miel y piloncillo o panela. Si bien el objetivo de las haciendas de caña era la elaboración de azúcar más o menos refinado (desde las calidades inferiores de azúcar prieta, pasando por la entreverada hasta llegar a la blanca), algunas de ellas únicamente fabricaban el piloncillo/panela/panocha o la miel, dadas la escasa dimensión y capacidad financiera disponible ${ }^{22}$. Como proceso productivo, todo dependía del uso que se diese al jugo obtenido en la molienda de la caña de azúcar. Si pasaba por la casa de calderas y la del purgar, entonces el resultado era el azúcar de caña; si únicamente se

Apuntamientos (1822), pp. 9-10.

García Cubas (1988 [1858]), [s. p.].

Scharrer (1997) y Sánchez Santiró (2001). 
concentraba en las calderas y se dejaba solidificar en moldes, el producto final era el piloncillo o la panela. Tanto la miel de caña, que era un esquilmo del azúcar, como las láminas y formas de panela, panocha y piloncillo, podían servir, tras su tratamiento, de materia prima para la fabricación de aguardiente de caña, el denominado chinguirito.

De esta breve descripción del proceso productivo podría inferirse que las haciendas azucareras y las fábricas de aguardiente de caña eran unidades conectadas únicamente por el hecho de compartir un producto, la miel. Sin embargo, en la medida en que el nivel tecnológico de la época hacía arduo y costoso su transporte, además de complicada la conservación — se avinagraba—, ambas actividades solían convivir en las haciendas azucareras. La localización del campo de cañas determinaba la ubicación de la casa de calderas, los purgares y, en menor medida, las fábricas de aguardiente.

\subsection{Azúcar}

En la primera mitad del siglo XIX, la producción azucarera regional —en sus diversas variedades: azúcar blanca, entreverada y prieta- evolucionó como recoge el Cuadro 1.

Globalmente, la fabricación de dulce en el período 1791-1851 presentó una tasa de crecimiento anual positiva, del orden del 1 por 100, si bien podemos distinguir varias etapas. Tras un escalón inicial que situaba la elaboración de azúcar en torno a las 5.200 Tm, las cuales aumentaron rápidamente con motivo de las excepcionales circunstancias que acaecieron tras la revolución de Haití en 1791, llegándose a producir más 7.800 al año ${ }^{23}$, se pasa a un lapso en el que las distintas fuentes (libros de colecturías de diezmos del arzobispado de México entre 1821 y 1832, y libros de alcabalas del Estado de México de 1834-1845) indican un retroceso al nivel de principios de la década de 1790.

En otro estudio hemos comprobado que los datos obtenidos para 1821-1845 presentaban una fuerte ocultación; de hecho, la producción de azúcar se hallaría en un nivel superior al del decenio de 1790, estando muy próximo al registrado a principios del siglo XIX, es decir, entre las 6.000 y 7.000 Tm. ${ }^{24}$. Estos indicadores muestran

23 Sánchez Santiró (2001), pp. 224-226.

24 Sánchez Santiró (2004), pp. 614-615. La evasión fiscal ya existía antes, pero se acentuó en las primeras décadas de vida independiente, en el contexto de la creación del estado-nación. En el tránsito de la Real Hacienda a la Hacienda Nacional se desarticuló la fiscalidad virreinal y sus mecanismos de control sin que el nuevo régimen consiguiese restablecerlos de manera rápida y efectiva (Marichal, 2001). 


\section{CUADRO 1}

PRODUCCIÓN DE AZÚCAR EN EL DISTRITO DE CUERNAVACA, 1791-1851

(promedios anuales en toneladas métricas)

\begin{tabular}{ccc}
\hline Períodos o años & Producción & Tasas de crecimiento (en \%) \\
\hline $\mathbf{1 7 9 1 - 1 7 9 4}$ & $5.216-$ \\
$\mathbf{1 8 0 0 - 1 8 0 4}$ & $7.8204,1$ \\
$\mathbf{1 8 2 1 - 1 8 3 2}$ & $5.350-1,8$ \\
$\mathbf{1 8 3 7 - 1 8 4 5}$ & $6.1180,8$ \\
$\mathbf{1 8 5 1}$ & $9.4643,1$ \\
\hline
\end{tabular}

Fuentes: Sánchez Santiró (2004).

una producción azucarera que apenas sintió los embates de la insurgencia a la vez que se adaptaba, tal y como veremos, a los cambios acaecidos por entonces en los ámbitos productivos y mercantiles tardocoloniales y de los primeros años de México como país independiente. El reacomodo y adaptación al nuevo contexto fue tal que, a mitad de la centuria, la producción de azúcar era claramente superior a la alcanzada en cualquier otro momento de la colonia, al superarse las 9.400 toneladas.

\subsection{Aguardiente de caña}

Pero no todo era azúcar en dicha agroindustria. Desde que se legalizó en 1796 la fabricación del aguardiente de caña, el denominado chinguirito, el análisis del sector no puede desligarse de éste, en la medida en que el permiso para su fabricación aumentó el valor económico de un esquilmo surgido de la producción azucarera, la miel, que era la materia prima básica del citado aguardiente ${ }^{25}$. Aprovechando la coyuntura, muchos hacendados azucareros, desde finales del siglo XVIII, instalaron fábricas de aguardiente, bien en sus haciendas, bien en ciertos pueblos y villas del distrito ${ }^{26}$.

Si sobre la evolución de la producción azucarera en el período 1791-1851 hay ciertas reservas y controversias, sobre los datos que poseemos acerca de la producción de chinguirito caben pocas dudas (véase el Cuadro 2).

25 Sánchez Santiró (2001), p. 78-91.

26 Sánchez Santiró (2001), p. 85, Orellana (1995), p. 70 y Memoria (1851). 


\section{CUADRO 2}

PRODUCCIÓN DE AGUARDIENTE DE CAÑA EN LAS ADMINISTRACIONES DE RENTAS

DE CUERNAVACA Y CUAUTLA/MORELOS, 1797-1851

(promedios anuales en barriles)

\begin{tabular}{ccccc}
\hline Años & Cuernavaca & Cuautla/Morelos & Total & Tasas de crecimiento (en \%) \\
\hline $\mathbf{1 7 9 7}$ & 6.2943 .529 & & 9.823 & - \\
$\mathbf{1 8 0 6}$ & 12.553 & n. d. & $19.000^{*}$ & $7,60^{*}$ \\
$\mathbf{1 8 3 3 - 1 8 3 4}$ & 19.69213 .790 & & 33.482 & 2,00 \\
$\mathbf{1 8 4 1 - 1 8 4 2}$ & 26.52616 .296 & & 42.823 & 3,10 \\
$\mathbf{1 8 5 1}$ & n. d. & n. d. & 41.616 & $-0,28$ \\
\hline
\end{tabular}

* Estimado.

Fuentes: Para 1797 y 1806, Sánchez Santiró (2001), pp. 84 y 86; para 1833-1834Memoria (1835), Estado 2; para 18411842, Archivo General de la Nación (AGN, en adelante), Dirección General de Rentas (DGR, en adelante), Morelos, caja 1, exp. 2 y 4; caja 37, exp. 7; y caja 40, exp. 4; para 1851, Memoria (1851).

La primera información regional disponible es de 1797. No obstante, la fuerte tasa de crecimiento (7,6 por 100 anual) obtenida de la comparación con la cifra de 1806 sugiere la existencia de una gran ocultación en aquel año, resultado de un ramo fiscal que apenas se estaba creando en la Real Hacienda, tratándose por tanto de un nivel mínimo de producción. La visita realizada por la Dirección General de Alcabalas foráneas a la administración de alcabalas de Cuernavaca en 1806 sacó a la luz que la producción de aguardiente se había duplicado con relación a 1797, superando los 12.000 barriles $^{27}$. Aunque desconocemos la producción en dicho año en la administración de rentas de Cuautla de Amilpas, suponemos que tuvo una evolución similar de modo que, a finales de la primera década del siglo XIX, la producción regional podría haber alcanzado los 18.000-19.000 barriles de aguardiente de caña. El siguiente dato, el de 1833-1834, se corresponde al total de barriles que declararon las administraciones de rentas de Cuernavaca, Morelos y Jonacatepec, sobre la base de 20 reales por barril quintaleño, lo que refleja una fabricación superior en casi un 76 por 100 a la de principios del Ochocientos. La cifra de 1841-1842, que abarca tanto los barriles guiados al principal mercado del área — la ciudad de México- como los remitidos al resto de entidades federativas, no así los guiados al propio departamento de México, eleva la cifra de producción a más de 42.000 unidades (unos 2

27 La unidad más empleada en la época era el barril quintaleño, que tenía una capacidad que oscilaba entre 46 y 50 litros de aguardiente (Lozano, 1995, pp. 168-171). 
millones de litros de aguardiente de caña). La última cifra, procedente de un informe de 1851 sobre los alambiques de aguardiente de caña existentes en la demarcación mexiquense, realizado por los hacendados de los distritos de Cuernavaca y Morelos para el gobierno del Estado de México, estimaba que la producción alcanzaba los 41.616 barriles al año. Esto implicaría que la producción de aguardiente de caña se habría estancado (con una tasa de crecimiento del -0,28 por 100 anual) en la misma década que la producción azucarera había acelerado su crecimiento. La explicación de esta aparente contradicción radica en que la Comisión de Hacienda del Estado de México procedió de dos maneras distintas: consideró una rebaja de un tercio en la miel producida, que iría a parar a otros usos, y que la cantidad de miel necesaria para fabricar un barril de aguardiente era de 20 arrobas. Esta proporción aludía a la variedad intermedia de la mencionada bebida alcohólica, la denominada campanilla, la cual, efectivamente, necesitaba entre 20 y 22 arrobas de miel por barril quintaleño de chinguirito. Sin embargo, si tenemos en cuenta que la variedad más amplia en el mercado no era ésta, sino la más económica, la de prueba de holanda (o descolorida), que sólo requería entre 16 y 18 arrobas de miel, entonces fácilmente se ve que la producción de aguardiente de caña del Estado de México a mediados del siglo XIX alcanzaba los 48.000 barriles $^{28}$. Así pues, esta consideración también arroja un balance positivo en lo que atañe a la producción de aguardiente de caña mexiquense en la primera mitad del siglo XIX, al implicar una tasa de crecimiento anual del 2 por 100 en el período $1806-1851^{29}$.

\subsection{Miel}

El tercer producto en importancia de la agroindustria azucarera era la miel, aunque ese nombre era un término genérico que englobaba una procedencia y usos diversos. Así, de la miel que se obtenía en la casa de calderas, la de "claros", una parte se entregaba a los trabajadores de la hacienda para su alimentación y otra se vendía o usaba como materia prima para la fabricación de aguardiente de caña. La que surgía del purgar de las haciendas era de dos tipos: la de "furos", que escurría de las formas de barro cocido donde se colocaba el melado para obtener los panes de azúcar, y la de "caras", que aparecía con la aplicación de barro en las mencionadas formas con el

\footnotetext{
28 Un barril quintaleño de prueba de holanda requería 16-18 arrobas de miel, y uno de campanilla entre 20 y 22; por su parte, el de calidad superior, llamado de prueba de aceite, llegaba a consumir entre 32 y 36 arrobas de miel (Hernández, 1974, pp. 131-132).

29 No realizamos el cálculo a partir de 1797, lo cual implicaría un crecimiento todavía mayor, puesto que, como ya indicamos, consideramos que los datos de ese año presentan una fuerte ocultación.
} 
propósito de blanquear el azúcar. Ambas podían emplearse como materia prima para la fabricación de aguardiente, aunque la mayor pureza de la miel de "caras" hacía que se reincorporase al melado de la casa de calderas para convertirla en azú$\operatorname{car}^{30}$.

Si bien hasta 1796, por la prohibición de fabricar aguardiente de caña en Nueva España, y a pesar de la producción fraudulenta, la importancia económica de la miel era mínima (incluso su almacenamiento era considerado un estorbo), con su legalización cambió radicalmente la situación. La condición de materia prima básica de una mercancía con alta demanda — el aguardiente de caña- en ciudades y reales mineros le otorgó un valor de cambio que saneó la vida económica de las haciendas azucareras $^{31}$.

No existe para la época tardocolonial, ni para las primeras décadas de México independiente, información detallada sobre el volumen de producción de miel en el estado/departamento de México. Sin embargo, por su condición de esquilmo con relación a la fabricación de azúcar, es posible realizar una estimación, si bien no exenta de problemas. Veámoslo.

En la mayoría de los documentos del siglo XVIII y de las dos primeras décadas del XIX que tratan sobre la fabricación de azúcar, cuando se cita a la miel, especialmente de "furos" y "claros", se establecía la siguiente proporción: por, aproximadamente, cada arroba de azúcar producida se generaba otra de miel (una arroba era igual a 11,5 Kg) ${ }^{32}$. No obstante, a raíz de la propuesta de 1828 de la Comisión de Hacienda del gobierno del Estado de México de instaurar una contribución directa sobre el cultivo de la caña y la fabricación de aguardiente, los hacendados elevaron una representación de protesta en la cual indicaban que, por cada 10 arrobas de azúcar se obtenía, cuando menos, entre 18 y 20 arrobas de miel, es decir, un 80-100 por 100 más de lo reconocido hasta entonces, sin haberse producido ningún cambio cualitativo en el proceso productivo ${ }^{33}$. Esta consideración al alza se mantenía en el informe sobre alambiques del Estado de México de 1851, aunque, en este caso, se manifestaba que por cada arroba de azúcar se obtenía una arroba y media de miel ${ }^{34}$. Esta última estimación de producción de miel del distrito de Cuernavaca hay que considerarla como un mínimo, ya que, si la relacionamos con la producción local de barriles de aguardiente, esto significaría que la totalidad de la miel obtenida se dedicaba a la elaboración de dicha mercancía, lo cual, como ya vimos, no era así. Sabemos que una parte de la producción de miel se comercializaba en otros distritos del Estado de

\footnotetext{
Scharrer (1997), pp. 136-144.

Lozano (1995); Sánchez Santiró (2001).

Apuntamientos (1822), p. 31.

Landázuri y Vázquez (1988), pp. 327-342.

Memoria (1851).
} 
CUADRO 3

ESTIMACIÓN DE LA PRODUCCIÓN DE MIEL EN EL DISTRITO DE CUERNAVACA, 1791-1851

(promedios anuales en toneladas métricas)

\begin{tabular}{ccc}
\hline Períodos o años & Producción & Tasas de crecimiento (en \%) \\
\hline $\mathbf{1 7 9 1 - 1 7 9 4}$ & 10.432 & - \\
$\mathbf{1 8 0 0 - 1 8 0 4}$ & $15.6444,10$ & $-1,20$ \\
$\mathbf{1 8 2 1 - 1 8 3 2}$ & $10.700^{*}$ & \\
$\mathbf{1 8 3 7 - 1 8 4 5}$ & $12.236^{* *} 0,96$ & 2,10 \\
$\mathbf{1 8 5 1}$ & 18.928 & \\
\hline
\end{tabular}

* Se consideró una producción de $6.000 \mathrm{Tm}$.

** Se estimó una producción de 7.000 Tm.

Fuentes: Sánchez Santiró (2004).

México y en el propio Distrito Federal. Todo lo cual nos hace suponer que en el distrito de Cuernavaca, en la primera mitad del siglo XIX, se obtenían, efectivamente, dos arrobas de miel por cada arroba de azúcar.

Tomando esta proporción, la producción de miel en el distrito durante el período 1791-1851 habría sido la que recoge el Cuadro 3.

Como orden de magnitud, el cuadro anterior presenta una evolución similar, como no podía ser de otra forma en un esquilmo con proporciones más o menos fijas, a la obtenida en la producción de azúcar del distrito de Cuernavaca, con un crecimiento anual del orden del 1 por 100 en el período 1791-1851. Por lo tanto, no vamos a presentar aquí un estudio por etapas que lo único que haría sería reproducir lo ya indicado para el azúcar.

En síntesis, este conjunto de datos y estimaciones manifiestan que la agroindustria azucarera del Estado de México superó sin graves dificultades el período insurgente, no obstante haber sido parte del teatro de operaciones bélicas. Con la independencia, la producción azucarera regional reinició el proceso de crecimiento que se prolongaría hasta mediados de siglo, a pesar de la ligera reducción experimentada en la década de 1820. Su movimiento ascendente determinó los volúmenes de fabricación de la miel, mientras que la elaboración del aguardiente de caña manifestó un crecimiento más continuo y sostenido. 


\section{Espacios y redes mercantiles}

Los mercados de la agroindustria azucarera del Estado de México de la primera mitad del siglo XIX estaban determinados por diversos factores, entre los que destacan el volumen y composición de la producción, los costes de fabricación, transporte y almacenaje, la existencia de regiones potencialmente competidoras (Michoacán, Jalisco, Veracruz, Sinaloa), así como la presencia de mercancías complementarias (el cacao o el café por lo que hace al azúcar y piloncillo) o sustitutas (el pulque o el llamado vino "mezcal" / tequila con relación al aguardiente de caña). De su combinación específica en el lapso 1821-1854 (concurrencia en la producción, ventaja comparativa costes de producción, redes de mercantilización, acceso al crédito, etc. - y ubicación espacial) surgió una geografía mercantil azucarera con dos características principales: el mantenimiento de los mercados de tradición colonial y su superación, al poder colocar directamente una parte de la producción, sobre todo de azúcar, en plazas ocupadas anteriormente por hacendados michoacanos, tapatíos o veracruzanos. No sólo esto, la fabricación de tres productos diferenciados de forma nítida, azúcar, aguardiente de caña y miel, configuraron otros tantos mercados altamente zonificados con sus propias lógicas económicas. A ellos nos vamos a referir a continuación.

\subsection{Los mercados del azúcar}

El primer elemento a considerar es el monto total comercializado. Para ello, hemos empleado los libros de guías de las administraciones de rentas del distrito ${ }^{35}$. El segundo es la estacionalidad. Del análisis de las remisiones en varios años ${ }^{36}$, resalta que el arribo del azúcar a los mercados ocurría principalmente en el primer semestre del año, una práctica establecida en la centuria anterior. Desde mediados del siglo XVIII, las haciendas azucareras de la zona de tierra caliente al sur de la ciudad de México (las alcaldías mayores de Cuernavaca y Cuautla de Amilpas) fueron cambiando sus pautas de producción de modo que, poco a poco, incorporaron la estacionalidad, aunque sin llegar a la concentración que supondría el corte de la caña en una única época, la zafra ${ }^{37}$. Varias razones conectadas, en mayor o menor medida,

\footnotetext{
35 En total suman 5.185 guías (Sánchez Santiró, 2004, p. 620).

36 Cuernavaca, años 1837-1838, 1838-1839, 1839-1840, 1841-1842, AGN, DGR, Morelos, caja 32, exp.3; caja 17, exp. 4; caja 23, exp. 9; caja 37, exp. 7; y caja 14, exp. 18. Jonacatepec, año 1841-1842, AGN, DGR, Morelos, caja 28, exp. 40. Morelos, años 1834, 1841-1842, 1842-1843, 1845 (diez meses), AGN, DGR, Morelos, caja 31, exp. 71; caja 1, exp. 2 y 4; caja 28 exp. 42 ; у caja 27 , exp. 9.

37 Scharrer (1997), pp. 52, 80-82, 86, 92, 105-106, 113, 115 y 123.
} 
con la climatología, lo explican. Con la llegada de la estación de las lluvias, por lo general en el mes de mayo, dos elementos interactuaban. De un lado, aumentaba la humedad en la caña, lo que reducía la concentración de sacarosa; si se efectuaba el corte en ese momento, disminuía la cantidad de azúcar generada. De otro, con las lluvias empezaba la siembra de las milpas (campos de maíz), que era el alimento básico de los trabajadores permanentes y temporales de las haciendas azucareras. La disminución de las actividades en la hacienda les permitía atender a su subsistencia y obtener ingresos para el pago de los arrendamientos a los hacendados, muchos de ellos en especie ${ }^{38}$. La otra razón fundamental de la estacionalidad, conectada también con el clima aunque en menor grado, eran las dificultades que las precipitaciones generaban en el transporte, al demorar y encarecer los envíos. Evitarlos o reducirlos entre los meses de mayo y octubre, aminoraba costes. El tercer factor a considerar es el de los puntos de destino a los que se dirigía el azúcar fabricado en el Estado de México (Cuadro 4) ${ }^{39}$.

En conjunto, unas $3.000 \mathrm{Tm}$ de azúcar (259.690 arrobas) eran guiadas cada año fuera del Estado de México desde ambas administraciones de rentas (desconocemos los envíos de la administración de Jonacatepec, así como los realizados mediante pases - de menor volumen y valor que las guías-y las ventas efectuadas en el interior de la entidad federativa), lo cual representaba un movimiento anual de entre 500 y 800 recuas de mulas ${ }^{40}$.

Los destinos de las guías muestran una clara concentración geográfica: el norte minero, en especial Durango, Chihuahua, Nuevo México y San Luis Potosí, al cual se dirigían anualmente entre 1,5 y 2 millones de kilogramos de azúcar fabricados en el lejano distrito de Cuernavaca. La siguiente zona eran los puertos del Golfo de México, sobre todo Veracruz, Tampico y Matamoros, descendiendo de manera notoria, seguidamente, las guías encaminadas a otras localidades. El grupo "otros", en especial el que surge del libro de guías de Cuernavaca de 1837-1838, distorsiona el

38 Sánchez Santiró (2001), p. 108.

39 Hemos agrupado los datos de las guías de azúcar de Cuernavaca y Morelos en cuatro zonas fundamentales: a) Norte minero, conformado por los estados norteños con fuerte presencia de la minería de metales preciosos (San Luis Potosí, Zacatecas, Durango, Chihuahua y Nuevo México), que suponían la mayoría de los destinos de las guías de azúcar del distrito de Cuernavaca. En esta zona se incluyen los escasos envíos realizados a Jalisco, Sonora y Aguascalientes; b) Costa del Golfo, que recoge las guías con destino a cinco puertos: Veracruz y Tuxpan (Estado de Veracruz), Tampico y Matamoros (Tamaulipas) y Campeche; c) Centro, zona constituida por los envíos dirigidos al Distrito Federal, Puebla, Tlaxcala, Querétaro, Morelia y Guanajuato; d) Otros, conformado tanto por los envíos a lugares distintos de los indicados como por aquellas guías que, por su configuración múltiple (por ejemplo, una con los destinos México y Durango, u otra destinada a Querétaro, Colima y Chihuahua), no es posible determinar a ciencia cierta el punto de destino del envío de azúcar asentado en la guía. 


\section{CUADRO 4}

ZONAS DE DESTINO DE LAS GUIIAS DE AZÚCAR DE LAS ADMINISTRACIONES DE RENTAS

DE LOS PARTIDOS DE MORELOS, 1834, Y CUERNAVACA, 1837-1838

(promedios anuales en arrobas y porcentajes)

\begin{tabular}{lcccccccc}
\hline Partidos & $\begin{array}{c}\text { Norte } \\
\text { minero }\end{array}$ & $\%$ & $\begin{array}{c}\text { Costa } \\
\text { del Golfo }\end{array}$ & $\%$ & Centro & $\%$ & Otros & \% \\
\hline Morelos (1834) & 88.174 & 65,8 & 31.995 & 23,9 & 7.076 & 5,3 & 6.815 & 5,0 \\
Cuernavaca (1837/38) & 64.792 & 51,6 & 12.882 & 10,2 & 5.229 & 4,2 & 42.727 & 34,0 \\
\hline Total & $\mathbf{1 5 2 . 9 6 6}$ & $\mathbf{5 8 , 9}$ & $\mathbf{4 4 . 8 7 7}$ & $\mathbf{1 7 , 3} \mathbf{1 2 . 3 0 5}$ & $\mathbf{4 , 7} \mathbf{4 9 . 5 4 2}$ & $\mathbf{1 9 , 1}$ \\
\hline
\end{tabular}

Fuentes: Sánchez Santiró (2004), p. 621.

panorama, ya que numerosas guías agrupan a dos y tres localidades en un único envío pasando por la ciudad de México. Sin embargo, gracias a los libros de la aduana del Distrito Federal de 1835-1836, hemos podido concluir que, aproximadamente, el 50 por 100 del azúcar que ingresaba a la ciudad volvía a salir con rumbo a otras aduanas de la República, en un movimiento que reproducía los destinos y porcentajes establecidos a partir de los libros de guías de las administraciones de rentas de los partidos de Morelos y Cuernavaca ${ }^{41}$ (véase el Mapa 1).

Para comprender la geografía mercantil del azúcar del distrito de Cuernavaca hay que atender a tres factores: la existencia de productores potencialmente competidores, la lógica económica de los hacendados azucareros del estado/departamento de México y la constitución de amplias redes mercantiles.

Por lo que hace al primer punto, sabemos que la producción azucarera michoacana y veracruzana sufrió graves destrucciones, llegándose incluso a la desaparición o abandono de los ingenios ${ }^{42}$. La recuperación productiva de estas zonas sería un hecho de la segunda mitad del siglo XIX, especialmente en el porfiriato.

Con relación a la lógica económica de los hacendados azucareros del estado/departamento de México, cabe plantear la siguiente hipótesis. El mantenimiento de la producción de una mercancía que implicaba altos costes, el azúcar —no así la miel, la panocha, el piloncillo o la panela—, dependía de su alta consideración 


\section{MAPA 1}

LOCALIDADES DE DESTINO DE LAS GUIAAS DE AZÚCAR DE LAS ADMINISTRACIONES DE RENTAS DE LOS PARTIDOS DE MORELOS Y CUERNAVACA, 1834, 1837-1838

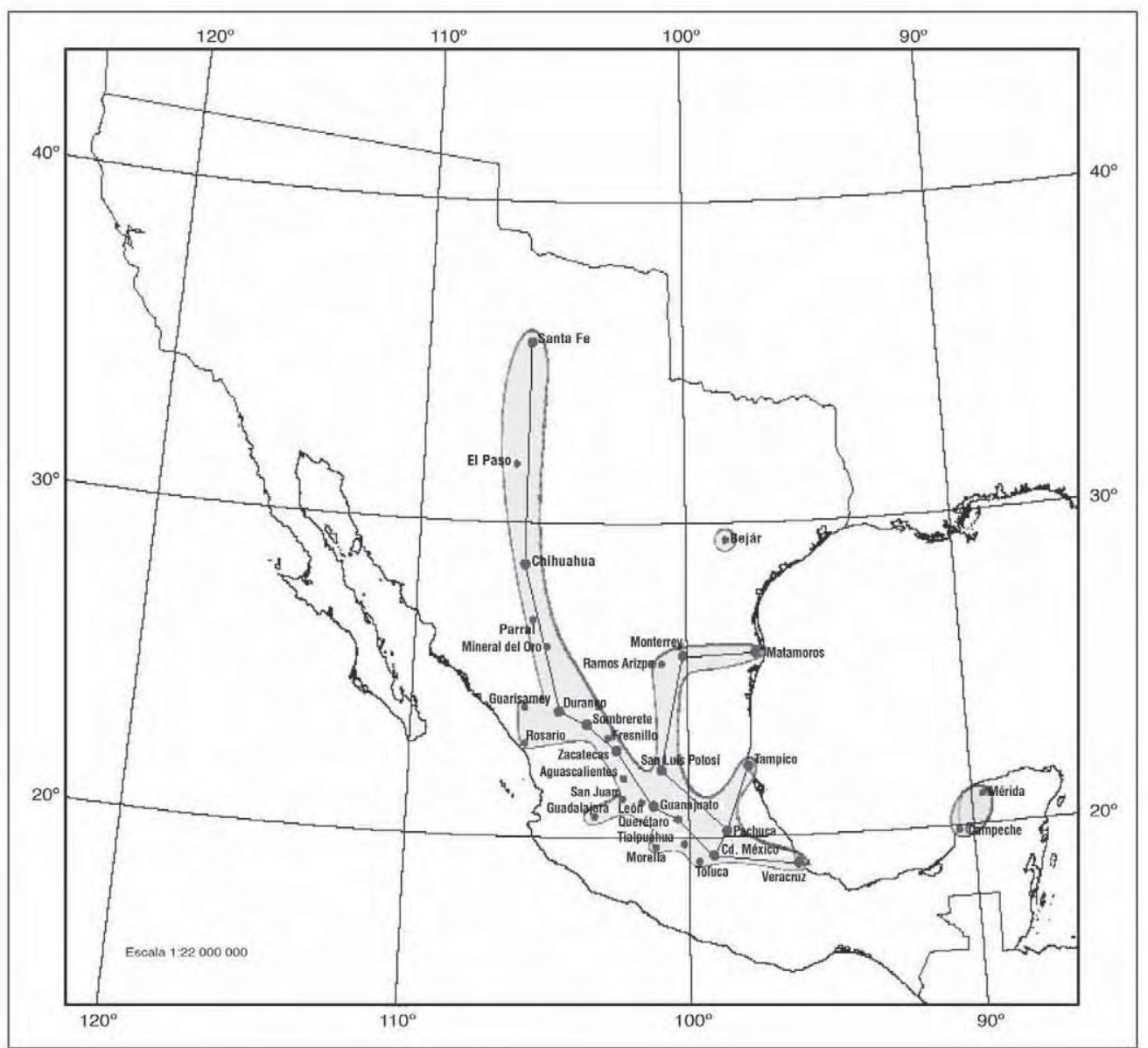

Fuente: AGN, DGR, Morelos, caja 31, exp. 71 y caja 32, exp. 3. Elaboró: Óscar Josué Jurado Gutiérrez

en el mercado, lo cual se reflejaba en los precios. Se trataba de una mercancía que se trasladaba, principalmente, a los centros mineros del noroeste, obteniendo a cambio una combinación de libranzas (letras de cambio) y de plata pasta o amonedada, que iba a circular en los mercados internos de la República y que, en el caso del metal precioso, tenía una capacidad de realización inmediata en los mercados internacionales. Como síntoma de esta lógica tenemos que muchas de las guías localizadas no sólo se orientaban a las capitales de los estados norteños (Chihuahua, Durango, 
Zacatecas, etc.), desde las cuales se redistribuiría el azúcar a los núcleos urbanos y los reales mineros próximos, sino que especificaban, como punto final, los propios reales, caso de Guarisamey, Mineral del Oro, Real de Catorce o Real de Jesús María ${ }^{43}$. En la medida en que la minería de Zacatecas, Guanajuato, Durango, Chihuahua y San Luis Potosí se fue recuperando en la segunda mitad de la década de 1820 y durante la de $1830^{44}$, los hacendados mexiquenses remitieron a dichos estados un tercio, al menos, de la producción azucarera (aproximadamente, unas $2.000 \mathrm{Tm}$ ). El restante 10 por 100 (unas 600 Tm) se orientó a tres puertos, Veracruz, Tampico y Matamoros, por este orden.

¿Qué se buscaba en estos últimos? La expectativa exportadora es poco verosímil, ya que sus precios no eran competitivos en el mercado internacional ${ }^{45}$. Por tanto, cabe suponer que el envío a los puertos tenía la misma lógica que las remisiones a los estados mineros norteños. Si consideramos que, desde mediados del decenio de 1830, salieron anualmente por el puerto de Tampico entre 4 y 5 millones de pesos procedentes de las zonas mineras del centro y el noroeste de la República y que, entre movimientos legales y clandestinos, se exportaban unos 2 millones de pesos por el puerto de Matamoros $^{46}$, el traslado de azúcar a ambos destinos, mediante una navegación de cabotaje desde Veracruz, permitiría a los hacendados azucareros obtener el mismo resultado que con su traslado directo al noroeste. Es razonable suponer que los arrieros que bajaban de los estados mineros (en especial, Chihuahua, San Luis Potosí, Durango y Zacatecas) ${ }^{47}$ a los puertos con envíos de plata amonedada (y, a veces, de plata pasta), regresasen con el azúcar mexiquense, además de mercancías extranjeras (en especial, textiles y vinos europeos). Por otra parte, el traslado de azúcar a los puertos facilitaba que los hacendados mexiquenses, además de libranzas, lograsen intercambiar el dulce por las mercancías de importación que algunos comerciantes nacionales hubiesen adquirido, a precios relativamente más bajos, dada la condición de puertos de entrada de productos foráneos. Unas compras que permitían su posterior reventa en los mercados urbanos y mineros del centro de la República, en especial la ciudad de México, así como en el lejano norte. En el caso del traslado de azúcar al puerto de Veracruz, este último procedimiento parece ser el más lógico ${ }^{48}$.

43 AGN, DGR, Morelos, caja 31, exp. 71; y Aduana del Distrito Federal, vol. 29, exp. 754.

44 Entre 1822 y 1850, la producción minera mexicana, medida por sus niveles de acuñación, experimentó un ritmo de crecimiento anual medio del 2,56 por 100, frente al 0,52 por 100 registrado entre 1851 y 1875 (Velasco, 1988, p. 42-44).

45 Lerdo (1967); Crespo (1988); Ibarra (1998).

$46 \quad$ Ibarra (1998), p. 180 y 193.

47 Este es uno de los elementos más claros de modificación de las pautas mercantiles respecto a la colonia. Ibarra (1998), p. 180-181.

$48 \quad$ Ibarra (1998), p. 232-233. 


\section{CUADRO 5}

ESTIMACIÓN DEL COSTE UNITARIO DEL TRANSPORTE DEL AZÚCAR, 1835-1836

\begin{tabular}{lcccccc}
\hline Destino & $\begin{array}{c}\text { Distancia } \\
(\mathbf{K m})\end{array}$ & $\begin{array}{c}\text { Días } \\
\text { (promedio) }\end{array}$ & $\begin{array}{c}\text { Precio de } \mathbf{~ K g} \\
\text { en México }\end{array}$ & $\begin{array}{c}\text { Coste fletes } \\
\text { (reales) }\end{array}$ & $\begin{array}{c}\text { Precio final } \\
\text { (reales) }\end{array}$ & $\begin{array}{c}\text { Incremento } \\
(\%)\end{array}$ \\
\hline Chihuahua & 1.693 & 84,6 & 1 real & 1,70 & 2,7 & +170 \\
Durango & 975 & 56,6 & 1 real & 0,97 & 1,9 & +97 \\
Zacatecas & 668 & 34,2 & 1 real & 0,66 & 1,6 & +66 \\
Veracruz & 402 & 27,0 & 1 real & 0,40 & 1,4 & +40 \\
Guanajuato & 365 & 23,5 & 1 real & 0,36 & 1,3 & +36 \\
Querétaro & 211 & 15,5 & 1 real & 0,20 & 1,2 & +20 \\
\hline
\end{tabular}

Fuentes: AGN, DGR, Morelos, caja 21, exp. 2; y Suárez (1997), p. 179.

El circuito mercantil (azúcar, plata y mercancías de importación) permite replantear el tradicional problema de la imposibilidad de trasladar productos agrícolas a puntos lejanos, dado el fuerte encarecimiento que provocarían los fletes y la fiscalidad alcabalatoria. Los datos registrados en el Cuadro 5 ilustran este punto ${ }^{49}$.

Se aprecia claramente lo que podía suponer el coste unitario de los fletes en el transporte a grandes distancias de productos alimenticios. Trasladar azúcar a los centros mineros del norte desde la ciudad de México, significaba incrementar el precio final entre un 66 por 100 y un 170 por 100, mientras que transportarla al puerto más próximo - Veracruz - lo elevaba un 40 por 100, sin incluir aquí el gravamen de la fiscalidad alcabalatoria, ni los diversos derechos que hubiese que afrontar en determinadas plazas y ciudades del país.

49 Dicho cuadro requiere una explicación. El precio del kilogramo de azúcar proviene del Libro de alcabalas de efectos del país de la aduana de México de 1835-1836; según éste, entraron en la ciudad 199.592 arrobas de azúcar con un valor aforado de 289.390 pesos, lo que arroja 1,4 pesos por arroba o, lo que es igual, 1,04 reales por Kg. Tomando éste como el precio en la ciudad de México y considerando que, en promedio, el coste del flete por Tm/Km en 1800 era de 11,85 granos (1 peso era igual a 8 reales, y 1 real igual a 12 granos), el traslado de $1 \mathrm{Kg}$ de azúcar a Chihuahua (a $1.693 \mathrm{Km}$ de la ciudad de México) significaba un flete de 1,7 reales por $\mathrm{Kg}$, lo cual arroja un precio final en destino de 2,7 reales por $\mathrm{Kg}$. Es decir, un incremento del 170 por 100 sobre el precio de origen. Así se ha procedido en el resto de casos. Este cálculo se ha hecho sabiendo que los fletes no eran fijos y que variaban según las épocas del año y los productos transportados; sin embargo, creemos que es una estimación promedio válida para poder ilustrar el problema del coste del transporte como barrera para el tránsito de mercancías. 
Ahora bien, si consideramos que el azúcar era uno de los productos alimenticios nacionales de mayor valor en el mercado ${ }^{50}$, y que el transporte ha de ser visto como un circuito que busca el traslado de mercancías en la ida y el retorno, las grandes distancias, con su corolario de costes, no eran un problema insalvable. A pesar de que el envío del azúcar a lugares como Chihuahua —a casi $1.700 \mathrm{Km}$ de la ciudad de México - o Durango - unos $1.000 \mathrm{Km}$ - elevaba considerablemente el precio final de aquélla, el retorno de las recuas de mulas cargadas de plata pasta o amonedada, con una relación de valor/peso mucho más elevada (1 Kg de azúcar $=1$ real; $1 \mathrm{Kg}$ de plata $=304,8$ reales $)^{51}$, permite suponer que el coste unitario total de los fletes (idaretorno) con relación al valor total de las mercancías disminuyese considerablemente. Además, el menor volumen de la plata que volvía en los retornos facilitaba que se cargasen otras mercancías, muchas veces con trayectos intermedios, lo cual reducía aún más el coste del transporte ${ }^{52}$. La conjunción de factores que confluían en este circuito lo convertía en un negocio de gran interés para los productores de azúcar del distrito de Cuernavaca, que posiblemente no hubiese podido existir si las haciendas azucareras de Michoacán, Veracruz o Jalisco hubiesen mantenido una producción elevada, la cual, además de surtir su propio mercado regional, les hubiese permitido proveer a los estados mineros del norte y a los puertos del Golfo de México.

La conexión entre los distintos espacios económicos insertos en este circuito se realizaba por medio de las redes mercantiles. En relación a las que se articularon en torno al azúcar (único aspecto que atendemos puntualmente en este trabajo), cabe apuntar que el sector prominente de los hacendados azucareros mexiquenses pudo colocar directamente la mayor parte del dulce en los mercados, en la medida en que

$50 \quad$ En el lapso 1792-1814, un kilogramo de maíz tenía un precio medio en la ciudad de México de 6,7 granos (Florescano, 1969, pp. 203-205), y, en 1794-1812, uno de trigo alcanzaba en el mismo mercado 7,1 granos (García Acosta, 1988, p. 131); por su parte, en 1791-1810, un kilogramo de azúcar tenía un precio medio de 16,9 granos (Sánchez Santiró, 2001, pp. 203-205). Por el contrario, un derivado muy barato de la caña de azúcar destinado al consumo de las capas populares era la panocha. En 1825, un kilogramo de panocha colorada (de mayor valor que la prieta) tenía un precio en el mercado de Cuernavaca de 5,5 granos, lo cual arroja un precio inferior al del alimento básico de la población, el maíz (AGN, DGR, Morelos, caja 39, exp. 56). De ahí el gran consumo de este derivado de la caña de azúcar entre la población de escasos recursos, ya como alimento en sí, ya como edulcorante.

51 Hemos considerado que la relación entre peso y valor de la plata en pasta y amonedada era equivalente, lo que no es cierto ya que la plata amonedada tenía un valor superior. Para establecer el precio de un kilogramo de plata se ha utilizado la siguiente equivalencia: un marco de plata era igual a 8 onzas (aproximadamente, 230 gramos), de donde un kilogramo era igual a 4,34 marcos de plata (Bakewell, 1976, p. 361). Si un marco de plata contenía 8,73 pesos (Hausberger, 1997, pp. 24-25), entonces un kilogramo de plata equivalía a 38,1 pesos (304 reales 8 granos).

52 Es evidente que los problemas de inseguridad incrementarían los costes del transporte de la plata en pasta y amonedada (véase Ibarra, 1998, pp. 172-200), sin embargo, el alto valor de este producto respecto a su peso debía de compensar con creces los mencionados costes generados por problemas de inseguridad. 
la titularidad de las fincas, de los ingenios azucareros más importantes y de su producción se mantuvo bajo el control de las antiguas familias propietarias de los ingenios. Unos linajes que compaginaban las actividades productivas y comercializadoras en diversos sectores, tales como los Eguía, García Monasterio, Gutiérrez de Lanzas, Icazbalceta, Manzano, Michaus, Velasco de la Torre o Yermo. Una manifestación del mencionado control la constituyen los almacenes/expendios de azúcar de la ciudad de México en la década de 1830 —eran veinticinco en 1832-, muchos de ellos propiedad de las antiguas familias de hacendados-comerciantes mencionadas ${ }^{53}$.

Estos hacendados-comerciantes, además de poseer el control sobre la producción de azúcar y su comercialización en el principal mercado del país, la ciudad de México, contaban con conexiones mercantiles en diversos núcleos urbanos, portuarios y mineros del centro y el norte, lo que les facilitaba la redistribución. El Cuadro 6 muestra el ejemplo de los envíos de azúcar efectuados en 1834 desde la hacienda del Hospital, propiedad de la familia Michaus, del partido de Cuautla-Morelos ${ }^{54}$.

Tal y como se aprecia en dicho cuadro, la hacienda del Hospital remitía cerca de 21.000 arrobas $(240 \mathrm{Tm})$ de azúcar al año a tres mercados fundamentales: Durango (el 57,2 por 100), Nuevo México (el 26,8 por 100) y Veracruz (el 10,1 por 100), a través de ocho consignatarios. En la medida en que el registro utilizado como fuente es alcabalatorio, no es posible perfilar con mayor detalle si los consignatarios que aparecen son comerciantes redistribuidores en los lugares de destino o empleados de los hacendados-comerciantes del centro del país localizados en aquéllos. Lo que resalta, en todo caso, es la capacidad de los hacendados azucareros del centro del país para enviar su producción a grandes distancias, salvando los obstáculos geográficos y fiscales. Cada hacendado azucarero generó una red mercantil semejante ${ }^{55}$.

53 Galván (1832), pp. 254-255.

54 En dicho año, la administración de alcabalas del partido de Cuautla-Morelos registró el envío de 134.060 arrobas de azúcar a diferentes destinos en 428 guías de azúcar. En ellas aparecen, entre otros datos, los nombres de los remitentes y consignatarios. Respecto a los primeros, por lo general, no aparecen los nombres de los propietarios o de los arrendatarios de las haciendas azucareras, sino el de sus administradores y empleados. En el caso de la hacienda del Hospital, de la familia Michaus, la mayoría del azúcar fue remitida por su administrador, José Domínguez, en concreto 20.299 arrobas, mientras que un monto muy inferior, 729 arrobas, fue remitido por un empleado de la propiedad, Nicolás Vázquez. Para los remitentes y las cantidades de azúcar enviadas desde dicho partido, AGN, DGR, Morelos, caja 31, exp. 71. Para los administradores y empleados de las haciendas del partido de Cuautla-Morelos en 1834, AGN, DGR, Estado de México, caja 241, exp. 16, y Morelos, caja 13, exp. 6.

55 Este aspecto lo hemos desarrollado en un trabajo de próxima publicación titulado "Las incertidumbres del cambio: redes sociales y mercantiles de los hacendados-comerciantes azucareros del centro de México (1800-1834)", el cual fue presentado en el XIV Congreso Internacional de AHILA. Europa-América: paralelismos en la distancia, organizado por la Universitat Jaume I/AHILA, en septiembre de 2005. 


\section{CUADRO 6}

COMERCIALIZACIÓN DEL AZÚCAR DE LA HACIENDA DEL HOSPITAL, 1834

\begin{tabular}{llr}
\hline Destino Consignatario & & Arrobas \\
\hline Chihuahua & Carrillo, Gabriel & 319 \\
Nuevo México & Carrillo, Gabriel & 4.928 \\
Veracruz & Cervantes 140 & \\
Veracruz & García, Mariano & 1.800 \\
México & Michaus, Miguel & 469 \\
Nuevo León & Michaus, Miguel & 363 \\
Nuevo México & Michaus, Miguel & 714 \\
Veracruz & Mosqueda, Victorino & 200 \\
Durango & Mújica, Manuel & 295 \\
Tetelco & Vázquez, Joaquín & 60 \\
Durango & Veraza, Manuel & 11.740 \\
\hline Total arrobas & & 21.028 \\
\hline
\end{tabular}

Fuentes: AGN, DGR, Morelos, caja 31, exp. 71.

\subsection{Los mercados del aguardiente de caña}

El aguardiente de caña constituía la segunda parte del binomio fundamental de la agroindustria azucarera del distrito de Cuernavaca. Una producción que, como vimos, basculaba entre 30.000 y 40.000 barriles en las décadas de 1820-1840. Para establecer los circuitos, hemos empleado la misma fuente que en el caso del azúcar ${ }^{56}$. A diferencia de los envíos de azúcar, el mercado del aguardiente de caña no presentaba estacionalidad. Del análisis de varios años de las remisiones de barriles de aguardiente de caña, ${ }^{57}$ destaca la uniformidad de los envíos, con un promedio mensual de 3.500 unidades. Es el ejemplo de una actividad económica marcada por fac-

56 Lo que supone que tengamos problemas semejantes, ya que el libro de guías de Morelos de 1834 es mucho más preciso al determinar los destinos de los envíos de aguardiente, mientras que el de Cuernavaca de 1837-1838, presenta dificultades a la hora de establecer el destino final de 5.037 barriles, lo cual representa el 20 por 100 del chinguirito guiado.

57 Cuernavaca, años 1837-1838, 1838-1839, 1839-1840, 1840-1841, 1841-1842, AGN, DGR, Morelos, caja 32, exp. 3; caja 17, exp. 4; caja 23, exp. 9; caja 37, exp. 7; caja 31 exp. 72, y caja 14, exp. 18. Jonacatepec, años 18411842, AGN, DGR, Morelos, caja 28, exp. 40. Morelos, años 1842-1843, 1845 — diez meses-, AGN, DGR, Morelos, caja 28, exp. 42, y caja 27, exp. 9. 


\section{CUADRO 7}

DESTINOS DE LAS GUIAS DE BARRILES DE AGUARDIENTE DE CAÑA

DE LOS PARTIDOS DE CUERNAVACA Y MORELOS, 1834-1838

\begin{tabular}{lc} 
Destinos Barriles & Porcentajes* \\
\hline México & $3.47517,3$ \\
Guanajuato & $3.15215,7$ \\
Pachuca/Real del Monte/Real Chico/Huasca & $1.1945,9$ \\
Toluca & $1.0925,4$ \\
Zumpango & 9004,5 \\
Tacubaya & 7933,9 \\
Metepec (Ixtlahuaca/Zinacantepec) & 6373,2 \\
Cuautitlán & 5953,0 \\
Maravatío & 3821,9 \\
San Ángel & 3701,8 \\
Querétaro & 2921,5 \\
Tlalpan & 2601,3 \\
Otros (hinterland de México, Toluca y Querétaro) & $\mathbf{5 9}$ \\
Indefinido & $6.98034,7$ \\
\hline
\end{tabular}

Total 25.159

* No incluye el destino "Indefinido".

Fuentes: AGN, DGR, Morelos, caja 31, exp. 71, y caja 32, exp. 3.

tores tecnológicos, esencialmente la diversa tipología de los alambiques (barro, olla y madera $)^{58}$, que le permitía escapar de factores medioambientales. Una vez elaborado el aguardiente, el riesgo de deterioro era mínimo, lo cual hacía posible que pudiese superar la estacionalidad de los purgares de las haciendas, estableciendo una dinámica mercantil ajustada a la demanda. Véase el Cuadro 7.

Lo primero que se comprueba es la menor amplitud espacial de los envíos de barriles de aguardiente respecto de los de azúcar. El radio de acción alcanzaba como límite significativo hacia el norte el núcleo minero de la ciudad de Guanajuato

59 Engloba numerosas localidades de mediana y pequeña dimensión que, en conjunto, aportan entre 0,1 y el 1 por 100 del total de envíos. Lo relevante de esto es que denota cómo el aguardiente de caña, a diferencia del azúcar, era un producto muy extendido entre el común de la población mexicana. 
(365 Km), reproduciendo básicamente la lógica económica de los envíos de azúcar. Así, durante los decenios de 1830 y 1840, el aguardiente de caña de Cuernavaca fue comercializado, por este orden, en su mercado tradicional, la ciudad de México y su hinterland (Tacubaya, Cuautitlán, San Ángel, Tlalpan, etc.) y en dos núcleos mineros relevantes, Guanajuato y Pachuca, a lo cuales hay que añadir otros centros urbanos de importancia dadas su dimensión demográfica, sus funciones administrativas y su actividad como centros de redistribución de mercancías, caso de Toluca y Querétaro. Es lógico suponer que con el abasto de aguardiente de caña a dichos mercados se pretendiese la obtención de plata y libranzas, o un intercambio por determinados productos con valor en el mercado (agropecuarios, textiles, etc.) para su posterior reventa ${ }^{60}$.

Sin embargo, no encontramos envíos relevantes a otras zonas norteñas o a los puertos $^{61}$. ¿Cuáles son las razones? Consideramos que dos son los factores que explican la ausencia de envíos a puntos clave del Golfo de México y a los reales mineros del septentrión mexicano. Primeramente, en el caso de las zonas denominadas de tierra caliente de los estados de Michoacán, Veracruz y Jalisco, el desarrollo del cultivo de la caña de azúcar con el propósito de fabricar piloncillo/panela o miel, no así azúcar, era algo bastante rápido y económico, lo cual significa que en esos lugares se podía desarrollar la producción de aguardiente de caña sin tener que realizar grandes inversiones ${ }^{62}$. La mayor proximidad a las zonas mineras del centro y norte del país, así como a los puertos del Golfo les ofrecía una clara ventaja con relación a las fábricas de aguardiente mexiquenses. En segundo lugar, otra producción realizaba funciones como sustituto del aguardiente de caña: el mezcal/tequila. Aunque carecemos de monografías que nos informen acerca de la producción de esta bebida alcohólica en el período (zonas productoras, volúmenes, precios, mercados, etc.), diversas memorias de hacienda y noticias estadísticas permiten apuntar algunas hipótesis.

De la información fiscal se deduce que la producción de mezcal estaba localizada en las décadas de 1830 y 1840 en el Estado de Jalisco, lo cual no obsta para que también se diese en Chihuahua, Sinaloa y Oaxaca, aunque en menores cantidades. Tenemos varios indicios de ello. En la noticia estadística sobre Jalisco, elaborada por

60 La menor distancia abarcada reducía considerablemente el problema del coste de los transportes, por lo cual el intercambio de aguardiente con, por ejemplo, productos agrícolas (caso de cereales) de escaso valor con relación al peso, se hacía factible, máxime si tenemos en cuenta que los intercambios se realizaban en los estados/departamentos más densamente poblados de la República.

61 Es sintomático que de las 647 guías de aguardiente de caña expedidas en 1834 desde la aduana de Morelos, sólo existan dos registros hacia puntos como Durango y Matamoros, con un monto total que no supera los 20 barriles, algo, por tanto, anecdótico. AGN, DGR, Morelos, caja 31, exp. 71. 
Longinos Banda en $1873^{63}$, hallamos que, en 1830, la contribución directa sobre alambiques recaudó 50.906 pesos, cantidad que se elevó a 78.366 pesos en 1831. Para poder calibrar lo que esto significa, basta compararlo con el total de recaudación estatal por alcabalas en dichos años (163.265 pesos y 160.949 pesos, respectivamente): supone, en promedio, el 40 por 100. Por tanto, un único ramo, dedicado a la fabricación de lo que en la época se denominaba "vino mezcal", constituía un rubro fundamental de la fiscalidad del Estado de Jalisco, tendencia que se mantuvo en el decenio de $1840^{64}$.

Lo importante de esta realidad es que, con una ubicación privilegiada respecto a los reales mineros norteños, localizados en los estados/departamentos de Chihuahua, Durango, Zacatecas y Nuevo México, la producción de mezcales de Jalisco pudo competir de forma ventajosa con la de aguardiente de caña del estado/departamento de México, bloqueándole, a través del mecanismo de los precios, el acceso a los mencionados mercados ${ }^{65}$.

\subsection{Los mercados de la miel}

La tercera producción en importancia de la agroindustria azucarera del distrito de Cuernavaca era la miel de caña. Su principal utilidad, como hemos comentado, radicaba en que era la materia prima básica para la fabricación del aguardiente. Desafortunadamente, con la información limitada de que disponemos sobre este rubro, el libro de guías del partido de Morelos de 1834, nuestro análisis sobre este producto y sus mercados ha de considerarse como un primer esbozo ${ }^{66}$.

El primer punto a dilucidar es el de la cantidad de miel susceptible de ser colocada fuera del distrito, y que, por tanto, no era consumida en la fabricación local de aguardiente. Sabemos que el rango mínimo de producción de miel, durante el lapso 1820-1840, estaría entre 10.000 y $14.000 \mathrm{Tm}$. ¿Qué parte quedaba libre para su comercialización? Con los datos de que disponemos no podemos contestar tajantemente a esta cuestión, ya que, en el único caso representativo localizado (las guías del partido de Morelos de 1834), el total de miel comercializada fuera del distrito fue de $1.750 \mathrm{Tm}$ (152.175 arrobas). ¿Debemos suponer que en el partido de Cuernavaca se hizo otro tanto, o más, dado su mayor extensión y número de

Olveda (1983).

Memoria (1844).

Memoria (1846), pp. 36-37.

AGN, DGR, Morelos, caja 31, exp. 71. El Libro de partidas de cargo y data de las guías expedidas, recibidas y tornaguías de 1834, contiene 953 envíos de miel. 


\section{CUADRO 8}

DESTINOS DE LAS GUIAS DE MIEL DEL PARTIDO DE MORELOS, 1834

\begin{tabular}{|c|c|c|}
\hline Destino Miel & (arrobas) & Porcentajes \\
\hline Tlalmanalco & $43.02628,3$ & \\
\hline Chalco & $21.23414,0$ & \\
\hline San Cosme & $20.55913,5$ & \\
\hline México & $13.4068,8$ & \\
\hline Ameca & $13.0898,6$ & \\
\hline Tetelco & $9.4616,2$ & \\
\hline Texcoco & $7.1954,7$ & \\
\hline Coatepec & $4.5543,0$ & \\
\hline Hacienda de la Compañía & $3.7352,5$ & \\
\hline Xochimilco & $2.4581,6$ & \\
\hline Tenango Tepopula & $2.1191,4$ & \\
\hline Compañía & $1.7231,1$ & \\
\hline Tenango & $1.5551,0$ & \\
\hline Coatepec Chalco & $1.5141,0$ & \\
\hline Totolapan & $1.2430,8$ & \\
\hline Otros destinos & $5.3043,5$ & \\
\hline Total 152.175 & & 100,0 \\
\hline
\end{tabular}

haciendas? ¿Cómo se comportaba el partido de Jonacatepec? ¿Permanecían, pues, unas 9.000-10.000 Tm en el distrito con destino a la fabricación de aguardiente? ¿Existían comportamientos diferenciales entre partidos del distrito, tal y como sucedía a finales del período colonial y parece traslucir la memoria del Estado de México de 1835 ? $^{67}$ Éstas son cuestiones que todavía no podemos contestar. Por la misma razón, no se puede plantear de forma plausible si existía un comportamiento estacional, o no, en las remisiones de miel fuera del distrito de Cuernavaca. Sin embargo, el panorama es más claro si atendemos a los destinos de las guías que recoge el Cuadro 8.

67 Sánchez Santiró (2001), pp. 74-78. Memoria (1835). Estado 1. 
La totalidad de los envíos se circunscribía al denominado en la época "distrito del Este", localizado a unos 40-50 Km de Cuernavaca (en especial, al partido de Chalco), y al Distrito Federal, concretamente a la ciudad de México y Xochimilco, lo cual arroja un radio de acción considerablemente inferior al del azúcar y al del aguardiente de caña. Si transportar en la época productos manufacturados como los dos últimos citados era costoso y lento, desplazar un líquido como la miel, de alta densidad, bajo precio relativo, problemas asociados a la variación de temperatura (peligro de avinagrarse) y difícil embalaje, era casi imposible. Además, existía la competencia que ejercían las ya citadas producciones regionales de miel de Michoacán, Jalisco, Sinaloa o Veracruz. Así, a pesar de que, entre 1828 y 1834, la miel estaba exenta del pago de alcabalas, sus envíos fuera de la entidad eran poco relevantes (apenas 56.347 arrobas, frente a una producción mínima estimada de 782.000 arrobas en la década de 1830, es decir el 7,2 por 100), tal y como se puede apreciar en la memoria del Estado de México de $1835^{68}$.

¿Cuál era la lógica de estos envíos? Básicamente respondía a dos elementos: el contrabando y la intención de evitar la fiscalidad que recaía sobre la fabricación del aguardiente de caña. Con relación al primer factor, el traslado de miel al distrito del Este (Tlalmanalco, Amecameca, Tenango, Chalco, etc.) y a Xochimilco permitía que, una vez transformada en aguardiente de caña, se pudiese burlar más fácilmente el pago de la fiscalidad alcabalatoria de la ciudad de México, mediante su introducción fraudulenta en recipientes de menor volumen que los barriles quintaleños (jarras, botellas, odres, etc.), a través del lago de Chalco y del de Xochimilco ${ }^{69}$. Respecto al segundo factor, la venta de miel en la ciudad de México suponía que el aguardiente de caña fabricado allí no tuviese que afrontar el pago del derecho de elaboración del Estado de México que, desde 1828, era de 20 reales por barril ${ }^{70}$. Este panorama se modificaría con la llegada del régimen centralista en 1835, el cual transformó la contribución directa sobre la producción en un impuesto indirecto sobre las ventas de miel y aguardiente realizadas fuera del departamento de México, atendiéndose así la postura de los fabricantes de aguardiente, así como la de los administradores de rentas del distrito de Cuernavaca, que abogaban por liberar de gravámenes a la producción.

\footnotetext{
$68 \quad$ Memoria (1835), Estado 1.

69 Un comportamiento que repetía las prácticas de finales del período colonial. AGN, Alcabalas, vol. 543, f. $261 \mathrm{v}$.

70 Téllez y Piña (s.f.), Tomo II, pp. 56-57.
} 


\section{Conclusiones}

La agroindustria azucarera mexiquense localizada en el distrito de Cuernavaca vivió una etapa de recuperación y expansión productiva entre 1821 y 1854 . Ya fuese en la fabricación de azúcar, aguardiente de caña o miel, su volumen de producción fue creciente, a pesar de la contracción de la renta y los mercados que vivía la economía mexicana de la primera mitad del siglo XIX.

El caso aquí analizado, parte de otros trabajos organizados con un enfoque regional y sectorial, matiza y puntualiza este panorama general de crisis, en el sentido de que el fenómeno de la regionalización/fragmentación de la economía mexicana no era un proceso inexorable, resultado necesario de la recesión, sino el producto de un cúmulo de circunstancias en el que influían, entre otros factores, la existencia de mercados potenciales, la conformación de productores en concurrencia, el desarrollo de mercancías sustitutas, la articulación de redes mercantiles y el papel jugado por los regímenes fiscales de la época en los distintos lugares de la geografía mexicana.

En la medida en que los dos principales mercados de México, el minero y el urbano, reemprendieron el crecimiento en las décadas de 1830 y 1840, tras la crisis del conflicto insurgente, fue posible que la agroindustria azucarera del distrito de Cuernavaca accediese a territorios que superaban la dimensión local o regional, al generar productos con alta valoración relativa en el país.

Por lo que hace a los mercados del azúcar, básicamente, los núcleos mineros del norte y los puertos del Golfo de México, además de su mercado tradicional, la ciudad de México, hay que decir que carecerían de lógica, dadas las distancias a recorrer, si no se considera la privilegiada situación que vivió el sector azucarero mexiquense, ante la reducción y práctica desaparición de competidores internos desde la insurgencia, caso de Veracruz o Michoacán, así como la prohibición de importar azúcar desde 1824. El acceso a aquellas plazas, con un comportamiento estacional muy marcado dada su dependencia de los ciclos agrícolas y las condiciones técnicas de la producción en la época, permitió que los fabricantes de azúcar del Estado de México se conectasen directamente a través de una tupida red mercantil con las principales zonas productoras y redistribuidoras de la plata mexicana y de las mercancías europeas y americanas de importación. Este circuito basado en tres vértices (azúcarplata-importaciones) hizo que los altos costes unitarios del transporte (en el caso de los envíos a zonas de Durango o Chihuahua, el precio del azúcar podía elevarse entre un 97 y un 170 por 100 respecto al que alcanzaba en la ciudad de México) se sobrellevasen, permitiendo la generación de utilidades. La escasa producción azucarera subsistente en otras zonas del país, a pesar de su mejor ubicación con relación a los mercados urbanos y mineros del norte, quedó abocada a nutrir la demanda de los estados y territorios de Querétaro, Michoacán, Jalisco, Aguascalientes, Colima, Guanajuato y parte de Zacatecas. 
En relación a los mercados del aguardiente de caña mexiquense, la lógica interna de funcionamiento fue muy semejante, aunque, en su caso, no se diese el fenómeno de la estacionalidad, al tratarse de un producto que no se echaba a perder fácilmente una vez elaborado: la búsqueda de los mercados mineros y urbanos (Guanajuato, Real del Monte, Pachuca, Real Chico, Toluca, México, Querétaro, etc.). Sin embargo, la menor complejidad técnica y las reducidas necesidades financieras para obtener las materias primas (miel y piloncillo/panocha/panela), así como para instalar los alambiques, facilitó la implantación de productores regionales en los estados/departamentos de Veracruz, Michoacán, Jalisco e, incluso, en el propio Guanajuato, la cual impidió la ocupación de los mercados norteños y portuarios del Golfo por los fabricantes mexiquenses. A todo ello coadyuvó la fuerte implantación en Jalisco, Sinaloa y Chihuahua de una mercancía obtenida a partir de la destilación del agave, capaz de sustituir al chinguirito, el denominado en la época "vino mezcal".

Los mercados de la miel, mucho más reducidos en volumen y precios, y con un mapa de distribución circunscrito a la ciudad de México y su hinterland (Chalco, Xochimilco, Texcoco, etc.), presenta ciertas características que lo perfilan como un espacio mercantil que seguía la lógica de la época tardocolonial: evitar una fiscalidad directa sobre la producción (el efecto buscado con las fábricas de aguardiente de caña situadas en la ciudad de México) o facilitar el contrabando (las producciones cercanas a los lagos y canales que rodeaban el sur y el oriente de la capital). Aquí tenemos un claro ejemplo de las distorsiones que el desigual sistema fiscal federal mexicano podía acabar generando en los mercados internos.

En síntesis, una agroindustria generadora de amplios circuitos mercantiles según productos, condiciones técnicas, necesidades de financiación, competidores potenciales, redes mercantiles y regímenes fiscales, que integraba diversas regiones productivas, caso del azúcar o del aguardiente de caña, o que quedaba circunscrita al ámbito local y regional, como el de la miel de caña. La orografía, el coste del transporte y la fiscalidad alcabalatoria implicaban dificultades, pero no eran obstáculos infranqueables para la articulación de determinadas producciones agroindustriales y manufactureras con regiones productoras de mercancías de alta demanda y valor en los mercados internos y externos, caso de la plata, pese a ser zonas lejanas y de difícil comunicación, o con los núcleos portuarios que introducían productos ultramarinos.

Lo relevante de este estudio es que muestra cómo, en un contexto de profunda reestructuración de los mercados internos mexicanos tras la independencia (consolidación y, en su caso, apertura de casas de moneda provinciales, papel preponderante de los puertos de Tampico y Matamoros en la extracción de plata y numerario, pérdida de influencia mercantil de la ciudad de México, etc.), no se produjo una desarticulación general de los mercados, tal y como nos hace suponer una parte de la historiografía, cuando plantea que, en las primeras décadas de vida indepen- 
diente, se intensificó el fenómeno de la regionalización económica y política, hablándose incluso de fragmentación. Un hecho que se añadiría (y reforzaría) al tradicional problema del alto coste de los transportes terrestres a causa de la vasta extensión y la difícil orografía del país. Por el contrario, el análisis de la agroindustria azucarera del Estado de México en el período 1821-1854 lo que muestra es la adaptación del sector a unos mercados que se estaban reformulando, cambiando rutas e incorporando a nuevos grupos de comerciantes nacionales y extranjeros. En la medida en que esto suponía la pérdida de control e influencia de las casas mercantiles capitalinas, el proceso fue vivido por estos actores como una etapa de crisis y fragmentación general.

\section{Bibliografía}

ALAMÁN, Lucas (1962): “Memoria sobre el estado de la Agricultura e Industria de la República, que la Dirección General de estos ramos presenta al Gobierno Supremo, en cumplimiento del Artículo 26 del Decreto Orgánico de 2 de diciembre de 1842. México, 1843", en La industria nacional y el comercio exterior (1842-1851), México, Publicaciones del Banco Nacional de Comercio Exterior, S. A., pp. 135-244.

APUNTAMIENTOS (1822): Apuntamientos sobre la necesidad de promover el cultivo del azúcar y otros frutos. Por medio de providencias que faciliten su extracción y hagan necesarios y útiles en los mismos frutos los retornos del comercio exterior, México, Oficina de D. José María Ramos Palomera.

BAKEWELL, P. J. (1976): Minería y sociedad en el México colonial. Zacatecas (1546-1700), México, Fondo de Cultura Económica.

CÁRDENAS SÁNCHEZ, Enrique (2003): Cuándo se originó el atraso económico de México. La economía mexicana en el largo siglo XIX, 1780-1920, Madrid, Biblioteca Nueva y Fundación José Ortega y Gasset.

CERUTTI, Mario (coord.) (1985): El siglo XIX en México. Cinco procesos regionales: Morelos, Monterrey, Yucatán, Jalisco y Puebla, México, Claves Latinoamericanas, Universidad Autónoma de Yucatán y Universidad Autónoma de Nuevo León.

CHOWNING, Margaret (1999): "Reevaluación de las perspectivas de ganancias en la agricultura mexicana del siglo XIX. Una perspectiva regional: Michoacán, 18101860", en HABER, Stephen (comp.), Cómo se rezagó la América Latina. Ensayos sobre las historias económicas de Brasil y México, 1800-1914, México, El Trimestre Económico, Fondo de Cultura Económica, 89, pp. 213-254.

COATSWORTH, John H. (1990): Los orígenes del atraso. Nueve ensayos de historia económica de México en los siglos XVIII y XIX, México, Alianza Editorial Mexicana. 
CRESPO, Horacio (dir.) (1988) y (1990): Historia del azúcar en México, 2 vols., México, Azúcar S. A. de C. V., y Fondo de Cultura Económica.

CRESPO, Horacio (1995): "Los precios del azúcar en Nueva España. Tendencias seculares y comportamiento cíclico", en GARCÍA ACOSTA, Virginia (coord.), Los precios de los alimentos y las manufacturas novohispanos, México, CIESAS e Instituto Mora, pp. 89-121.

CRESPO, Horacio, VEGA VILLANUEVA, Enrique (1988): Estadísticas históricas del azúcar en México, México, Azúcar S. A. de C. V.

DÍEZ, Domingo (1982): Bosquejo histórico geográfico de Morelos, México, Suma Morelense.

FLORESCANO, Enrique (1969): Precios del maíz y crisis agrícolas en México (17081810), México, El Colegio de México.

GALVÁN RIVERA, Mariano (1832): Calendario manual y guía de forasteros de Méjico para el año de 1832, México, Imprenta a cargo de Mariano Arévalo.

GARAVAGLIA, Juan Carlos, y GROSSO, Juan Carlos (1991): “El comportamiento demográfico de una parroquia poblana, de la colonia al México independiente: Tepeaca y su entorno agrario, 1740-1850", Historia Mexicana, 40, 4, pp. 615-671.

GARCÍA ACOSTA, Virginia (1988): Los precios del trigo en la historia colonial de México, México, CIESAS.

GARCÍA CUBAS, Antonio (1988 [1858]): Atlas geográfico, estadístico e histórico de la Republica Mexicana, 1858, México, Miguel Ángel Porrúa [Edición príncipe: México, Imprenta de José Mariano Fernández de Lara, 1858].

HERNÁNDEZ PALOMO, José (1974): El aguardiente de caña en México, 1724-1810, Sevilla, Escuela de Estudios Hispano-Americanos.

HAUSBERGER, Bernd (1997): La Nueva España y sus metales preciosos. La industria minera colonial a través de los libros de cargo y data de la Real Hacienda, 1761-1767, Madrid, Vervuert-Iberoamericana.

HUMBOLDT, Alejandro de (1966 [1803]): Ensayo político sobre el reino de Nueva España, México, Editorial Porrúa.

IBARRA BELLÓN, Araceli (1998): El comercio y el poder en México, 1821-1864, México, Fondo de Cultura Económica y Universidad de Guadalajara.

LANDÁZURI BENÍTEZ, Gisela y VÁZQUEZ MANTECÓN, Verónica (1988): Azúcar y estado, 1750-1880, México, Secretaría de Energía, Minas e Industria Paraestatal, UAM y Fondo de Cultura Económica.

LERDO DE TEJADA, Miguel (1967): El comercio exterior de México desde la conquista hasta hoy, México, Banco Nacional de Comercio Exterior S. A.

LOZANO ARMENDARES, Teresa (1995): El chinguirito vindicado. El contrabando de aguardiente de caña y la política colonial, México, UNAM.

MARICHAL, Carlos (2001): “Una difícil transición fiscal. Del régimen colonial al México independiente, 1750-1850", en MARICHAL, Carlos, y MARINO, Danie- 
la (comps.), De colonia a nación. Impuestos y política en México, 1750-1860, México, El Colegio de México, pp. 19-58.

MEMORIA (1835): Memoria de Hacienda, justicia y negocios eclesiásticos que el secretario del Gobierno del Estado de México encargado de dichos ramos leyó al H. Congreso en los días 4 y 5 del mes de abril de 1835, Toluca.

MEMORIA (1844): Memoria de la Hacienda Nacional de la República Mexicana presentada a las cámaras por el ministro del ramo en julio de 1844, México, Imprenta de José María Lara.

MEMORIA (1846): Memoria sobre el estado de la agricultura e industria de la republica en el año de 1845, que la Dirección general de estos ramos presenta al Gobierno Supremo, en el actual, de 1846, en cumplimiento del Art. ${ }^{\circ} 26$ del decreto orgánico de 2 de diciembre de1842, México, Imprenta de José Mariano Lara.

MEMORIA (1851): Memoria que el Secretario de Hacienda leyó al Honorable Congreso del Estado de México el día 3 de abril de 1851, Toluca, Imprenta de J. Quijano.

MORENO FRAGINALS, Manuel (1978): El Ingenio. Complejo económico social cubano del azúcar, 3 vols., La Habana, Ed. de Ciencias Sociales.

OLVEDA, Jaime (1983): El sistema fiscal de Jalisco (1821-1888), Guadalajara, Gobierno del Estado de Jalisco.

ORELLANA, Ignacio (1995): Descripción geográfica y estadística del distrito de Cuernavaca, 1826, México, CIESAS.

OROZCO Y BERRA, Manuel (1854): “La ciudad de México”, en Diccionario universal de historia y de geografía. Tomo V, México, Imprenta de F. Escalante y Cía., pp. 601-783.

ROMERO SOTELO, María Eugenia, y JÁUREGUI, Luis (1986): “Comentarios sobre el cálculo de la renta nacional en la economía novohispana", Investigación Económica, XLV, 177, pp. 105-140.

SALVUCCI, Richard J. (1999): "El ingreso nacional mexicano en la época de la independencia, 1800-1840", en HABER, Stephen (comp.), Cómo se rezagó la América Latina. Ensayos sobre las historias económicas de Brasil y México, 1800-1914, México, El Trimestre Económico, Fondo de Cultura Económica, 89, pp. 255-285.

-(2005): "Algunas consideraciones económicas (1836). Análisis mexicano de la depresión a principios del siglo XIX", Historia Mexicana, LV: 1, 217, pp. 67-97.

SALVUCCI, Richard J., y SALVUCCI, Linda K. (1993): "Las consecuencias económicas de la independencia mexicana", en PRADOS DE LA ESCOSURA, Leandro, AMARAL, Samuel (eds.), La independencia americana: consecuencias económicas, Madrid, Alianza Universidad, pp. 31-53.

SÁNCHEZ DÍAZ, Gerardo (1979): El Suroeste de Michoacán. Estructura económicosocial 1821-1851, Morelia, Universidad Michoacana de San Nicolás de Hidalgo.

SÁNCHEZ SANTIRÓ, Ernest (2001): Azúcar y poder. Estructura socioeconómica de las alcaldías mayores de Cuernavaca y Cuautla de Amilpas, 1730-1821, México, Universidad Autónoma del Estado de Morelos y Editorial Praxis. 
-(2004): “Producción y mercados de la agroindustria azucarera del distrito de Cuernavaca en la primera mitad del siglo XIX", Historia Mexicana, LIII, 3, pp. 605-646.

SANTAMARÍA GARCÍA, Antonio (2005): “Reformas coloniales, economía y especialización productiva en Puerto Rico y Cuba, 1760-1850", Revista de Indias, LXV, 235, pp. 709-728.

SCHARRER TAMM, Beatriz (1997): Azúcar y trabajo. Tecnología de los siglos XVII y XVIII en el actual Estado de Morelos, México, CIESAS, Instituto de Cultura de Morelos y Miguel Ángel de Porrúa.

SUÁREZ ARGÜELLO, Clara Elena (1997): Camino real y carrera larga. La arriería en la Nueva España durante el siglo XVIII, México, CIESAS.

TÉLLEZ, G., y PIÑA L., Mario e Irma (s. f.): Colección de decretos del Congreso del Estado de México (formato cd-rom), México, LIV Legislatura del Estado de México.

THOMSON, Guy P. C. (1989): Puebla de los Ángeles: Industry and Society in a Mexican City, 1700-1850, San Francisco, Westview.

VELASCO ÁVILA, Cuauhtémoc, y otros (1988): Estado y minería en México (17671910), México, Fondo de Cultura Económica-SEMIP.

WARD, Henry G. (1981): México en 1827, México, Fondo de Cultura Económica. 